\title{
Detección y cuantificación de virus dengue 2 en lisado celular y plasma de niños por qPCR en tiempo real usando un estuche comercial y el equipo Eco ${ }^{T M}$ System-Illumina
}

\author{
Detection and quantification of dengue virus 2 in culture supernatant \\ and plasma of children by qPCR using a commercial kit and the \\ Eco ${ }^{\text {TM }}$ System-Illumina device
}

Federico Perdomo Celis', Piedad Perilla', Doris M. Salgado 1,2 , Carlos F. Narváez ${ }^{\text {* }}$

\section{Resumen}

Métodos para diagnóstico de dengue virus (DENV) en zonas endémicas son altamente necesarios. Uno de ellos es la reacción en cadena de polimerasa en tiempo real (qPCR), método que permite además la cuantificación del genoma viral. Los estuches comerciales de qPCR para DENV son costosos y restringen su uso a un número pequeño de dispositivos de qPCR, limitando la aplicación de la técnica. Aquí se evaluó el desempeño de un estuche comercial de qPCR para la detección de DENV-2 en un dispositivo de qPCR (Eco ${ }^{T M}$ System, Illumina) localmente disponible, no listado por el fabricante del estuche. Lisado de células VERO-76 y plasma de niños, ambos con infección confirmada por DENV-2, fueron evaluados. Como controles de especificidad, lisado celular y plasma de niños infectados con DENV-1, además de lisado no infectado, fueron también incluidos. Las reacciones fueron además evaluadas simultáneamente en un equipo Applied Biosystem 7300, uno de los recomendados por el fabricante del estuche. La curva estándar generada por el Eco ${ }^{T M}$ fue robusta $\left(R^{2}=\right.$ $0.99)$, con baja variabilidad en las réplicas ( $<10 \%)$. La eficiencia de la reacción fue buena (88.8\%) y sólo hubo amplificación en los lisados y plasma de niños infectados con DENV-2. Hubo una fuerte correlación positiva $\left(R^{2}=\right.$ 1.0, $P=0.0028$ ) entre el número de copias de $A R N$ viral en las muestras detectadas por los dos dispositivos de qPCR usados. Así, el uso del estuche para detección de DENV-2 aquí probado puede extenderse al Eco ${ }^{T M}$ de forma segura.
Este trabajo fortalece la capacidad tecnológica para el estudio de DENV en un área endémica.

Palabras clave: PCR en tiempo real, dengue, diagnóstico de dengue, estuche comercial, Dispositivo de PCR en tiempo real.

\begin{abstract}
Methods for Dengue virus (DENV) diagnosis in endemic areas are greatly needed. One of them is the real-time polymerase chain reaction ( $q P C R$ ) that also enables to quantitate the viral genome. Kits of qPCR for DENV are expensive and restrict their use to a small number of qPCR devices, which limits the application of the technique. Here, we evaluated the performance of a commercial kit of qPCR to DENV-2 detection on a locally available qPCR device (Eco ${ }^{T M}$ System, Illumina), not cited by the kit manufacturer. VERO-76 cells lysate and plasma from children, both with confirmed ongoing DENV-2 infection, were evaluated. As specificity control, cell lysates and plasma from children infected with DENV-1, and uninfected lysate, were also included. The reactions were simultaneously evaluated in an Applied Biosystems 7300 device. The standard curve generated by $E c o^{T M}$ was robust $\left(R^{2}=0.99\right)$ with low variability in the replicates $(<10 \%)$. The reaction efficiency was high (88.8\%) and signal was only obtained in lysates and plasma infected with DENV-2. There was a strong positive correlation $\left(R^{2}=1.0, P=0.0028\right)$ between the
\end{abstract}

1. Semillero de Formación SINEDIR, Grupo de Parasitología y Medicina Tropical, Programa de Medicina, Universidad Surcolombiana, Neiva, Colombia

2. Servicio de Pediatría, Hospital Universitario de Neiva, Colombia Datos de contacto: Dr. Carlos Fernando Narváez. Correo electrónico: cfnarvaez@usco.edu.co Recibido: 01/06/2014 - Revisado: 02/06/2014 - Aceptado: 30/06/2014 
number of copies of viral RNA in the samples detected by both qPCR devices. Thus, the use of the evaluate kit for detection of DENV-2 here tested can be extended to Eco ${ }^{T M}$. With this work, technological capacity for DENV study in an endemic zone is greatly strengthened.

Keywords: Real-time polymerase chain reaction, dengue, Diagnosis, commercial kits, Real-time PCR device.

\section{Introducción}

El dengue constituye la arbovirosis más importante a nivel mundial por su alta morbi-mortalidad e impacto económico y social. Se estima que 390 millones de infecciones ocurren anualmente en el mundo y debido a la localización del vector en áreas tropicales, más de 2.5 billones de personas están en riesgo de infectarse ${ }^{1}$. Colombia no es ajena a éste problema y en el último año se presentaron 61,649 casos de dengue, el 3.3\% de ellos fueron formas severas de la infección. Localmente, el Departamento del Huila es un área hiperendémica para el virus, con 1,231 casos severos (17.3\%) del total nacional en las recientes epidemias entre los años 2010 y $2012^{2}$.

El dengue virus (DENV) pertenece al género Flavivirus, está compuesto de una membrana lipídica que envuelve la cápside y su genoma está conformado por ácido ribonucleico (ARN) de cadena sencilla y polaridad positiva ${ }^{3}$. Para el diagnóstico de la enfermedad se requieren criterios clínicos y de laboratorio. Varios métodos diagnósticos están disponibles para éste propósito y pueden ser clasificados como directos (detección de proteínas virales, amplificación de su genoma o aislamiento viral) o indirectos (detección de anticuerpos específicos para DENV) ${ }^{4}$. Para la detección del genoma viral comúnmente es utilizada la reacción en cadena de polimerasa por transcripción inversa $(\mathrm{RT}-\mathrm{PCR})^{5}$. Esta técnica se basa en la transcripción del ARN a ácido desoxirribonucleico (ADN) utilizando transcriptasas inversas, para posteriormente realizar la amplificación del segmento de interés gracias a polimerasas dependientes de ADN. La reacción puede llevarse a cabo en uno o dos pasos (la síntesis del ADNc y su amplificación se hacen en un mismo tubo, o por separado). Además puede ser anidada o semianidada, es decir, primero se realiza la reacción con primers externos para amplificar una región de $\mathrm{ADN}$ extensa que contiene el segmento de interés y luego utilizar éste producto como molde para una segunda PCR con uno (semianidada) o dos (anidada) primers internos para amplificar la región específica ${ }^{6}$.

Una variación de ésta es la PCR en tiempo real (qPCR), que tiene como característica fundamental la posibilidad de determinar el número de copias de $\mathrm{ARN}$ viral ${ }^{7}$. En la qPCR se introducen moléculas fluorescentes que se unen a los ácidos nucleicos y permiten detectar la amplificación del segmento de interés al tiempo en que van ocurriendo los ciclos de la reacción, calculando finalmente la cantidad relativa (veces de incremento en la amplificación del gen de interés en comparación con la de un gen de concentración conocida) o absoluta (determinación a través de una curva estándar generada por la dilución seriada de un control positivo) del genoma viral ${ }^{8}$. Se ha propuesto que la qPCR tiene ventajas sobre la PCR convencional, como por ejemplo el ser más sensible que ésta 9 .

Existen diversos protocolos de detección, serotipificación y cuantificación de DENV por qPCR. Su diferencia se basa principalmente en la química fluorescente utilizada, si se utilizan reacciones en uno o dos pasos o si se detectan uno o más serotipos al mismo tiempo
(qPCR en formato multiplex). Las moléculas fluorescentes de detección de la amplificación más frecuentemente utilizados son los intercaladores de ADN de cadena doble, como SYBR Green ${ }^{10,11}$ y las sondas de hidrólisis fluorescentes, como Taqman ${ }^{9,12,13}$. Los primeros emiten fluorescencia cuando se unen a ADN de cadena doble, mientras que los segundos lo hacen cuando la molécula de detección se separa de otra que inhibe su fluorescencia ${ }^{7}$. En el caso de las reacciones en uno o dos pasos, se prefieren los primeros porque se minimiza la probabilidad de contaminación de la muestra y la variación entre las reacciones enzimáticas ${ }^{14,15}$. Como característica, la mayoría de éstos emplean sondas de hidrólisis tipo Taqman ${ }^{16,17}$.

Actualmente para el diagnóstico de dengue en humanos existe sólo aprobado un estuche de qPCR desarrollado por el centro para el control y prevención de enfermedades (CDC) y aprobado por la FDA (del inglés Food and Drugs Administration) de Estados Unidos ${ }^{18}$ y se ha demostrado que tiene alta sensibilidad y especificidad $^{19}$. Éste permite la detección de los cuatro serotipos virales en muestras de plasma o suero a través de una reacción en un sólo paso utilizando sondas de hidrólisis tipo Taqman, siendo el ABI 7500 Fast Dx (Applied Biosystem) el único equipo recomendado para la aplicación del estuche. Sin embargo, en distintos laboratorios se han desarrollado ensayos de qPCR para la detección de DENV con fines investigativos ${ }^{20,21}$ y además existen varios estuches comerciales con el mismo propósito que han demostrado un buen rendimiento ${ }^{22}$. Una limitación importante para el uso de éstos últimos es su alto costo y el bajo número de equipos de qPCR recomendados por cada uno de ellos para llevar a cabo el ensayo, la mayoría de equipos no disponibles en regiones alejadas y endémicas. Esto limita enormemente la aplicación de la técnica y el posible impacto en el diagnóstico rápido de la infección. Aquí, se realizó la detección y cuantificación de DENV-2 por qPCR en lisado celular y plasma de niños infectados usando el estuche comercial de detección Dengue Virus II Real Time RT-PCR Kit (Shanghai ZJ Bio-Tech Co) aplicado en el equipo de qPCR Eco ${ }^{\text {TM }}$ System (Illumina, San Diego, CA), que no ha sido listado entre los dispositivos recomendados para la aplicación del respectivo estuche comercial, pero que está localmente disponible. Además, se comparó simultáneamente con un segundo equipo recomendado por los fabricantes del estuche.

\section{Materiales y métodos}

\section{Pacientes y muestras}

Dos niños agudamente infectados con dengue fueron incluidos en éste estudio. Para el diagnóstico de dengue se emplearon los criterios revisados de la OMS 2009 presentes en la guía integrada de pacientes con dengue, Colombia 2010. Previo consentimiento y asentimiento informado, dos a cuatro mililitros de sangre total fueron tomados de cada niño en tubos con EDTA, ambos casos en la etapa aguda de la infección (primeros 5 días de iniciada la fiebre). La sangre fue centrifugada a $300 \times \mathrm{g}$, el plasma separado, alicuotado y conservado a $-70^{\circ} \mathrm{C}$ hasta su uso para detección del antígeno NS1 viral y de las inmunoglobulinas (Ig) M, G específicas para DENV (Panbio, Alere, Australia) y la RT-PCR convencional.

\section{Elisa para diagnóstico de dengue}

Para la detección en plasma de IgM e IgG específicas de DENV y la proteína NS1 viral se emplearon los estuches comerciales Dengue 
IgM capture Elisa (Ref: E-DEN01M), Dengue IgG capture Elisa (Ref: E-DEN02G) y Dengue Early Elisa (Ref: E-DEN02P), respectivamente (todos de Panbio, Alere, Australia), siguiendo todas las instrucciones del fabricante. Brevemente, para la detección de las Igs, $100 \mu \mathrm{L}$ de las muestras, controles y calibrador diluidos $1 / 100$ en el diluyente proveído por el estuche, fueron añadidos a la placa cubierta con anticuerpo anti-IgM o IgG humanas. Luego de una hora de incubación a $37^{\circ} \mathrm{C}$, se lavó la placa y se añadieron $100 \mu \mathrm{L}$ del antígeno viral previamente mezclado con el anticuerpo anti-dengue conjugado a peroxidasa. Se incubó nuevamente por una hora a $37^{\circ} \mathrm{C}$ y luego de un lavado, se reveló con $100 \mu \mathrm{L}$ de tetrametilbenzidina (TMB). La reacción fue detenida con $100 \mu \mathrm{L}$ de ácido fosfórico $1 \mathrm{M}$. La lectura se realizó a $450 \mathrm{~nm}$ (referencia 600-650 nm) en un equipo ELx 800 (BIO-TEK Instruments, Winooski, Estados Unidos). En la detección de la proteína NS1, $100 \mu \mathrm{L}$ de las muestras, controles y calibrador diluidos al medio fueron añadidos a la placa cubierta con el anticuerpo anti-NS1. Luego de una hora de incubación a $37^{\circ} \mathrm{C}$ la placa se lavó y se añadieron $100 \mu \mathrm{L}$ del anticuerpo anti-NS1 conjugado a peroxidasa. Se incubó nuevamente la placa por una hora a $37^{\circ} \mathrm{C}$, y luego de otro paso de lavado, se reveló y se leyó como se describió previamente.

\section{Amplificación de DENV-I y 2 en cultivo celular}

DENV-1 y 2 fueron amplificados en cultivo de células VERO-76 (adquiridas desde el ATCC, Número: CRL-1587D). Quinientos $\mu \mathrm{L}$ de sobrenadante de cultivo con DENV-1 y 2 (amablemente proveídos por Iván Darío Vélez, Universidad de Antioquia, Colombia) fueron añadidos a una monocapa de células VERO-76 con un 70\% de confluencia. Éstas se incubaron en medio DMEM 1X y SFB al 2\% (ambos de GIBCO, Carlsbad, Estados Unidos; Cat: 11965-126 y $16000-044$, respectivamente) a $37^{\circ} \mathrm{C}$ y $5 \%$ de $\mathrm{CO}_{2}$. Al 5 día de cultivo se verificó la aparición de efecto citopático sobre la monocapa por microscopía óptica invertida y posteriormente el sobrenadante de los cultivos se recolectó, se centrifugó y se congeló a $-70^{\circ} \mathrm{C}$ hasta su uso. Como control, se recolectó el sobrenadante de cultivo celular no infectado tratado de forma idéntica a la ya descrita. La pureza del serotipo de DENV infectante fue determinada por RT-PCR convencional realizada como se describe abajo.

\section{Aislamiento del ARN para la RT-PCR y qPCR}

Para la purificación del ARN se utilizó el estuche comercial QIAmp viral RNA (QIAGEN, Valencia, CA, Cat: 52906), siguiendo todas las recomendaciones del fabricante. Brevemente, $140 \mu \mathrm{L}$ de las muestras fueron mezclados con buffer AVL y “carrier" de ARN e incubados a temperatura ambiente por $10 \mathrm{~min}$. Luego se añadieron $560 \mu \mathrm{L}$ de etanol al $100 \%$ y tras 2 pasos de centrifugación a $6,000 x g$ por un min se pasaron $1,260 \mu \mathrm{L}$ de la solución total por la columna correspondiente. Posteriormente se realizaron 2 lavados con $500 \mu \mathrm{L}$ de buffer AW1 y AW2 y se hizo la elución con $40 \mu \mathrm{L}$ de buffer AVE. La concentración de ARN aislado de cada condición fue determinada usando el equipo NanoDrop 2000 (Thermo, Wilmington, Estados Unidos), obteniendose una mediana de $98.7 \mathrm{ng} / \mu \mathrm{L}$ (rango 91-119.7).

\section{Detección y tipificación de DENV en lisado y plasma por RT-PCR convencional}

El serotipo infectante en las muestras analizadas fue determinado por RT-PCR convencional como previamente ha sido reportado ${ }^{5,23}$.
$5 \mu \mathrm{L}$ del ARN previamente aislado fueron añadidos a una mezcla que contenía $\mathrm{KCl} 50 \mathrm{mM}$, Tris $10 \mathrm{mM}(\mathrm{pH} 8.5)$, Triton $\mathrm{X}-100$ $0.1 \%$, gelatina $0.01 \%$, cada uno de los cuatro desoxinucleótidos trifosfato (DNTPs) a una concentración de $2.5 \mathrm{mM}, \mathrm{MgCl}_{2} 1.5$ $\mathrm{mM}$, ditiotreitol $5 \mathrm{mM}$, primers externos e internos (serotipo-específicos) a una concentración de $1 \mu \mathrm{g} / \mu \mathrm{L}$ y $5 \mathrm{U} / \mu \mathrm{L}$ de $T a q$ ADN polimerasa (Promega Corp., Madison, Wis) Las secuencias de los primers serotipo-específicos usados fueron las siguientes: DENV1: 5'-TCA ATA TGC TGA AAC GCG CGA GAA ACC G-3'; DENV-2: 5'-TTG CAC CAA CAG TCA ATG TCT TCA GGT TC-3'; TS1: 5'-CGT CTC AGT TGA TCC GGG GG-3'; TS2: 5'CGC CAC AAG GGC CAT GAA CAG-3'. La transcripción inversa y la amplificación se llevaron a cabo en un termociclador Veriti ${ }^{\mathrm{TM}}$ (Applied Biosystem). El perfil térmico usado fue: $42^{\circ} \mathrm{C}$ por 60 minutos, seguido de 35 ciclos de amplificación a $94^{\circ} \mathrm{C}$ por 45 segundos, $60^{\circ} \mathrm{C}$ por 45 segundos y $72^{\circ} \mathrm{C}$ por 1 minuto, con una extensión final a $72^{\circ} \mathrm{C}$ por 7 minutos.

\section{PCR en Tiempo Real}

Para la amplificación y cuantificación de DENV-2 se empleó un estuche comercial (Shanghai ZJ Bio-Tech Co, Shanghai, China, Cat: ER-0063-04), que emplea para la detección una sonda fluorescente tipo Taqman. Se siguieron todas las instrucciones del fabricante. Brevemente, $9 \mu \mathrm{L}$ de Super Mix, $0.5 \mu \mathrm{L}$ del mix enzimático y $0.5 \mu \mathrm{L}$ del control interno (para detectar la inhibición de la PCR) fueron mezclados con $2.5 \mu \mathrm{L}$ del control positivo (cuatro diluciones seriadas $1: 10$, iniciando en $1 \times 10^{7}$ copias $/ \mathrm{mL}$ ), del control negativo (agua libre de nucleasas) o del ARN extraído de las muestras. Debido a la capacidad de los pozos del dispositivo de qPCR utilizado, el volumen final de la reacción se ajustó a $12.5 \mu \mathrm{L}$ y no $25 \mu \mathrm{L}$ como recomienda el estuche comercial. Cada muestra, excepto el control negativo, se analizó por duplicado. El perfil térmico que se empleó fue: $45^{\circ} \mathrm{C}$ por 10 minutos, 1 ciclo; $95^{\circ} \mathrm{C}$ por 15 minutos, 1 ciclo; $95^{\circ} \mathrm{C}$ por 15 segundos y $60^{\circ} \mathrm{C}$ por 60 segundos, 40 ciclos; la fluorescencia fue medida a $60^{\circ} \mathrm{C}$. La reacción se llevó a cabo en el equipo Eco ${ }^{\mathrm{TM}}$ System (Illumina, San Diego, CA). Los datos fueron analizados con el software proveído por el equipo (EcoStudy software versión 5.0). La sensibilidad y el rango de detección del ensayo fueron $1 \mathrm{X} 10^{3}$ copias $/ \mathrm{mL}$ y $2 \mathrm{X} 10^{3}-1 \mathrm{X} 10^{8}$ copias $/ \mathrm{mL}$, respectivamente ${ }^{24}$. Se tomó como cut off un $\mathrm{Cq}$ (ciclo en el que cada muestra sobrepasó el umbral de detección) de 37 ciclos.

\section{Análisis Estadístico}

El análisis estadístico se hizo con el software GraphPad Prism 5.0. Para hallar el grado de correlación entre variables se utilizó el coeficiente de determinación, tomando como significativo un valor de $\mathrm{P}<0.05$. Para propósitos estadísticos, a las muestras con número no detectable de copias se les asignó un valor arbitrario de 500 copias/ $\mathrm{mL}$ (la mitad del límite de sensibilidad del ensayo).

\section{Resultados}

\section{Pacientes incluidos}

Se incluyeron dos niños de 13 y 14 años, uno de sexo masculino y otro femenino, que ingresaron al Departamento de Pediatría del Hospital Universitario de Neiva. Ambos consultaron en los prime- 
ros 5 días de iniciada la fiebre. Los dos casos correspondieron clínicamente a dengue grave. El diagnóstico y tipo de infección se confirmó a través de la detección de NS1, IgM e IgG específicas en plasma. Ambos pacientes presentaron infección secundaria (relación $\mathrm{IgM} / \mathrm{IgG}$ virus específicas $<1.8$ ). En la Tabla 1 se describen los resultados de las pruebas de Elisa realizadas para el diagnóstico de los pacientes.

Tabla 1. Resultados de las pruebas de Elisa realizadas para el diagnóstico de los pacientes

\begin{tabular}{lcc} 
Paciente & Sev 56 & Sev 61 \\
\hline Edad (años) & 14 & 13 \\
\hline Día de fiebre & 4 & 5 \\
\hline NS1 (Unidades Panbio) & 19 & 19 \\
\hline $\lg M$ (Unidades Panbio) & 22 & 28 \\
\hline $\lg G$ (Unidades Panbio) & 38 & 17 \\
\hline
\end{tabular}

\section{DENV-I y 2 fueron los virus presentes en lisado celular y plasma, detectados por RT-PCR convencional}

La pureza del serotipo amplificado por cultivo en células VERO76 fue determinada por RT-PCR convencional (Figura 1). Para ambos casos se emplearon controles positivos (lisados celulares, previamente tipificados) de cada uno de los serotipos virales. Con el protocolo usado se amplifican segmentos de la proteína preM de DENV-1 y 4 y de la proteína C (de la cápside) de DENV-2 y 3. Como ha sido previamente descrito y como es mostrado en la Figura 1, los productos de amplificación de DENV-1, 2, 3 y 4 generaron bandas de 482, 119, 290 y 389 pb, respectivamente ${ }^{23}$.
La tipificación del DENV en el plasma de los niños mostró que los serotipos infectantes fueron DENV-1 y 2 (Figura 1B). Todas las muestras fueron tipificadas por lo menos dos veces, obteniendo similar resultado en cada análisis. Así, DENV-1 y DENV-2 fueron los serotipos infectantes detectados tanto en lisado celular (Figura 1A) como en plasma de niños con la forma severa de la enfermedad (Figura 1B).

\section{Detección de DENV-2 en lisado y plasma por qPCR}

Para la detección y cuantificación específica de DENV-2, ARN purificado de cada condición fue analizado usando un estuche comercial aplicado en el equipo Eco ${ }^{\mathrm{TM}}$. Para conocer el número absoluto de copias de genoma viral $/ \mathrm{mL}$, se realizó la curva estándar proveída por el estuche que consta de cuatro diluciones seriadas del control positivo. Como muestra la Figura 2A, la curva estándar mostró un coeficiente de determinación del 99\% y la amplificación tuvo una eficiencia del $88.8 \%$. Este resultado demuestra que con el Eco ${ }^{\mathrm{TM}}$ se puede detectar y cuantificar DENV-2 de forma eficiente con el estuche empleado.

Usando la curva estándar y el $\mathrm{C}_{\mathrm{q}}$, de forma automatizada se determinó el número de copias de genoma viral de DENV-2 por mililitro en cada una de las muestras. Como se observa en la Figura $2 \mathrm{~B}$, muestras con infección por DENV-2 previamente confirmada por RT-PCR convencional tuvieron altas concentraciones de ARN viral, con un $\mathrm{Cq}$ que fue mucho menor a 37 (mediana 21, rango 1428). De notar, en el caso del lisado celular infectado por éste serotipo, la concentración de ARN viral fue incluso mayor al punto más alto de la curva estándar. En contraste, muestras de lisado celular y plasma con infección por DENV-1 o el mock, tuvieron un $\mathrm{Cq}>37$ (mediana 40) y la concentración de ARN viral fue menor al límite de detección del ensayo $\left(<1 \times 10^{3}\right.$ copias $\left./ \mathrm{mL}\right)$ (Tabla 2). También, como se observa en la Tabla 2 , la diferencia del valor entre los duplicados fue menor al 10\%, demostrando la baja variabilidad del ensayo.
A.

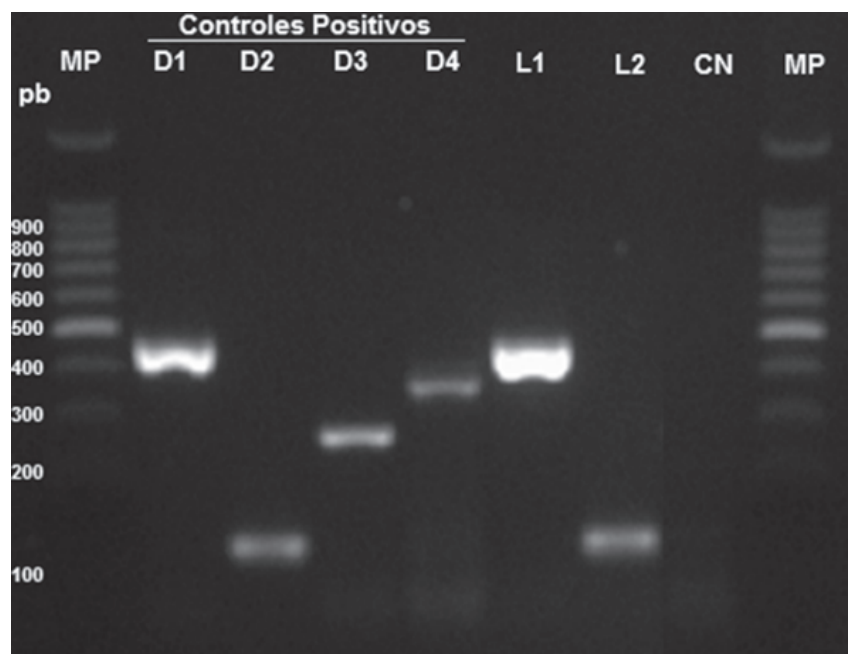

B.

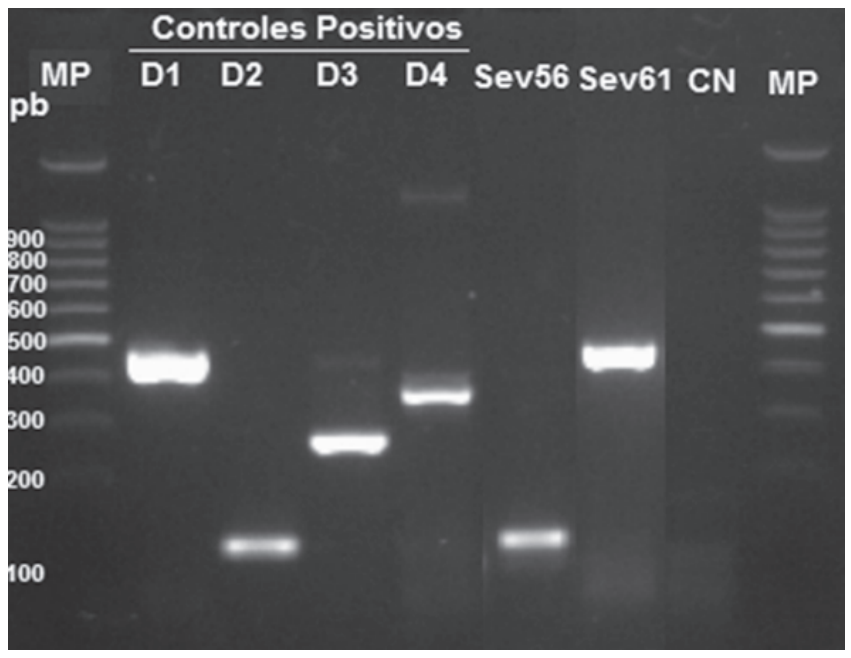

Figura 1. Serotipificación de las muestras de lisado celular (A) y plasma de niños (B) infectados con DENV por RTPCR convencional. MP: Marcador de peso; D1: Virus Dengue 1; D2: Virus Dengue 2; D3: Virus Dengue 3; D4: Virus Dengue 4; Sev 61 y Sev 56: Plasma de niños con infección por DENV; L1 y L2: Lisados celulares infectados con DENV1 y 2, respectivamente; $\mathrm{CN}$ : Control negativo. 
Tabla 2. Número de copias de ARN de virus dengue 2 en las muestras, analizadas por duplicado

Concentración de virus dengue 2 (copias $/ \mathrm{mL}$ )

Muestra

$\mathrm{Cq}$

Duplicado

\begin{tabular}{lccc} 
& & 1 & 2 \\
\hline Lisado celular no infectado & 40 & $500^{*}$ & $5 R^{* *}$ \\
\hline Lisado celular infectado con DENV-1 & 40 & $500^{*}$ & $500^{*}$ \\
\hline Lisado celular infectado con DENV-2 & 14 & $5 \times 10^{11}$ & $5.8 \times 10^{11}$ \\
\hline Plasma Sev 61 & 40 & $500^{*}$ & $500^{*}$ \\
\hline Plasma Sev 56 & 28 & $5.5 \times 10^{7}$ & $6.5 \times 10^{7}$
\end{tabular}

*Valor arbitrario asignado (mitad del límite de sensibilidad del ensayo)

**No realizado

A.

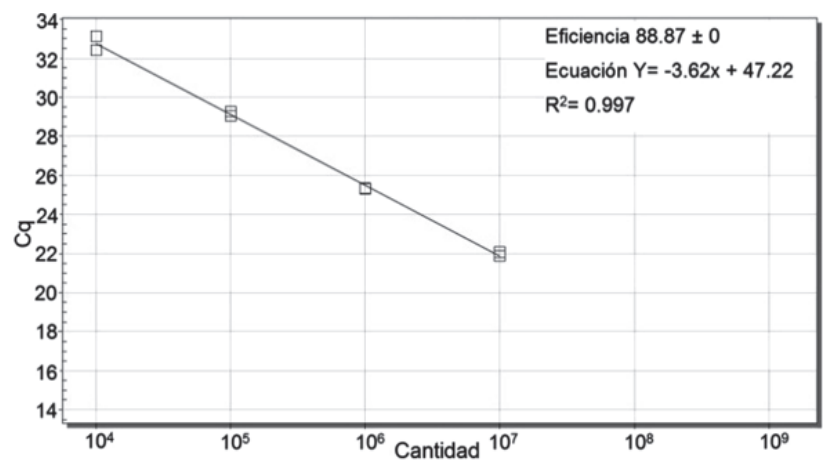

B.

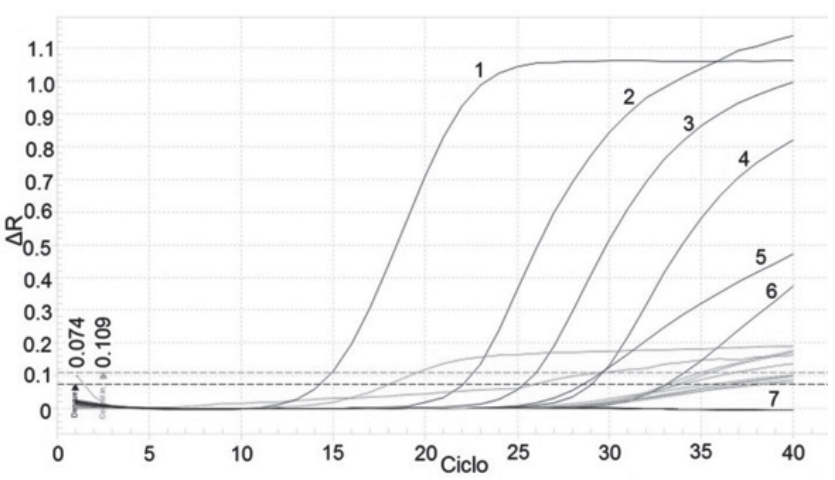

Figura 2. A. Curva estándar del estuche generada por el equipo Eco ${ }^{T M}$ System, Illumina. En el eje $Y$ se encuentra el ciclo de cuantificación $(\mathrm{Cq})$, o ciclo en el que la señal de fluorescencia cruzó el umbral de detección, y en el eje $X$ se encuentra la cantidad del gen presente en cada muestra (escala logarítmica). Cada cuadro representa un punto de la curva, analizados por duplicado (diluciones seriadas $1: 10$, partiendo desde $1 \times 10^{7}$ copias $/ \mathrm{mL}$ hasta $1 \times 10^{4}$ copias $/ \mathrm{mL}$ ). En la esquina superior derecha se muestran la eficiencia de la amplificación en cada ciclo de la qPCR, la ecuación de la curva y el $R^{2}$ de ésta. B. Amplificación linear $(\Delta R$; unidades de fluorescencia normalizada al ruido de fondo en cada pozo) de las muestra a través de los ciclos de PCR en Eco ${ }^{T M}$. Las líneas a trazos cortos azul y verde representan el umbral de detección para las muestras $(0,074)$ y para el control interno de inhibición de la PCR $(0,109)$, respectivamente; todas las muestras que sobrepasaron éste umbral fueron cuantificadas. Cada línea azul representa a una muestra o estándar y las líneas verdes representan sus respectivos controles internos de amplificación. 1: Lisado celular infectado con DENV-2; 2: Control positivo, $1 \times 10^{7}$ copias $/ \mathrm{mL}$; 3 : Control positivo, $1 \times 10^{6}$ copias $/ \mathrm{mL}$; 4 : Control positivo, $1 \times 10^{5}$ copias/ $\mathrm{mL}$; 5: Plasma de niño con infección por DENV-2; 6: Control positivo, 1X104 copias/mL: 7: Lisado celular no infectado, lisado celular infectado con DENV-1 y plasma de niño con infección por DENV-1.

\section{El rendimiento del Eco ${ }^{\mathrm{TM}}$ y el Applied Biosystem 7300 para la detección de DENV-2 usando el estuche de Shanghai ZJ Bio-Tech Co es comparable}

Debido a que el equipo Eco ${ }^{\mathrm{TM}}$ no es listado entre los dispositivos recomendados para la cuantificación de DENV-2 con el estuche comercial de Shanghai ZJ Bio-Tech Co, se comparó el desempeño de éste con uno de los dispositivos recomendados por el mismo, el Applied Biosystem (ABI) 7300 (Applied Biosystem, Foster City,
CA). La amplificación de las muestras se realizó simultáneamente en ambos equipos bajo las mismas condiciones previamente descritas (cada muestra por duplicado). Como es mostrado en la Figura 3, una fuerte correlación positiva fue encontrada entre el número de copias por mililitro de genoma de DENV detectados por los dos equipos. En resumen, a pesar de que el $\mathrm{Eco}^{\mathrm{TM}}$ no es recomendado por los fabricantes del estuche comercial Dengue Virus II Real Time RT-PCR Kit (Shanghai ZJ Bio-Tech Co) para la aplicación del ensayo, su desempeño es comparable al del equipo ABI 7300. 


\section{Discusión}

Por qPCR, usando un estuche comercial y el equipo $\mathrm{Eco}^{\mathrm{TM}}$ se realizó la detección y cuantificación de DENV-2 en lisado celular y plasma de niños con infección natural por DENV, previamente serotipificados por RT-PCR convencional. En ambos tipos de muestras se detectó DENV-2 de forma específica y con un desempeño eficiente.

Se incluyeron dos muestras de plasma de niños con infección aguda por DENV diagnosticada y confirmada por la detección en plasma del antígeno viral NS1, IgM e IgG específicas para el virus. Ambas muestras fueron tomadas en los primeros 5 días de iniciada la fiebre y el serotipo infectante se determinó por RT-PCR convencional. Igualmente fueron analizados lisados celulares obtenidos de la infección de células VERO-76 con DENV-1 y 2. En los últimos años se han descrito diversos protocolos y estuches comerciales de detección y cuantificación de DENV en fluidos biológicos o en sobrenadantes de cultivos o lisados celulares, todos con fines investigativos. La mayoría de ellos son costosos y poco accesibles, además de estar restringidos a un número limitado de dispositivos de qPCR. Ya que localmente se dispone del equipo Eco ${ }^{\mathrm{TM}}$, se evaluó su utilidad en la detección de DENV-2 (un serotipo viral altamente circulante en la región) con un estuche comercial, ya que éste último no lo lista dentro de los dispositivos para realizar el ensayo. Como química fluorescente, el estuche contiene sondas tipo Taqman, utilizadas en la mayoría de protocolos descritos para el análisis de $\mathrm{DENV}^{25}$. Ésta proporciona una menor tasa de falsos positivos en comparación con SYBR Green y evita tener que realizar análisis de curvas de "melt" para la detección de dímeros de primers". Adicionalmente el ensayo incluye como control interno el fluorocromo VIC/JOE, que, además de permitirnos identificar una posible inhibición de la PCR (que puede ser causada por una mala calidad de la muestra o una alta concentración del ARN o ADN), también sirve como señal de referencia para que las variaciones en la fluorescencia de cada pozo (causada por ejemplo por errores en el pipeteo) sean normalizadas automáticamente en relación al ruido de fondo de la reacción por el dispositivo de qPCR, por lo tanto, la fluorescencia de un pozo no es afectada por la del pozo adyacente.

El número absoluto de copias de DENV-2 fue determinada a través de la realización de una curva estándar del control positivo incluido en el estuche (cuantificación absoluta) ${ }^{26}$. Sin duda, la cuantificación absoluta se prefiere sobre la relativa pues determina la cantidad exacta de copias, a pesar de la limitación de tener que contar con una concentración conocida del gen de interés ${ }^{27}$. La curva estándar obtenida en el ensayo tuvo una pendiente de -3.62, con una eficiencia de la PCR del $88.8 \%$, es decir que la amplificación de las hebras molde de ADNc fue cercana al doble en cada ciclo de la PCR; de igual manera, hubo una correlación del $99.7 \%$ entre el Cq y las concentraciones de ADNc de la muestra de la curva estándar (Figura 2A). Estos valores son importantes para la confiabilidad de los cálculos de la cuantificación absoluta, pues son una medida de la optimización de la PCR a lo largo de los ciclos ${ }^{7}$. En general se acepta que la curva estándar debe tener una pendiente entre -3.68 y -3.10 , con una eficiencia mayor del $85 \%$ y un coeficiente de correlación mayor del $90 \%{ }^{11,25}$. Todos los Cq de las muestras positivas para DENV-2 estuvieron por debajo de 37, valor que el CDC recomienda como cut off en éste tipo de ensayos por las bajas probabilidades de que se presenten falsos positivos con este valor ${ }^{19}$. Las muestras con infección por DENV-1 confirmada por RT-PCR convencional tuvieron $\mathrm{Cq}$ mayores a 37 y por lo tanto se consideraron negativas para el serotipo 2 (Figura 2B, Tabla 2). Debido a que en nuestra región más del $90 \%$ de los casos de dengue son producidos por DENV-1 y 2 (Narváez CF, resultados no publicados), era crítico determinar si el ensayo podría diferenciar de forma segura y específica estos dos serotipos. El estuche empleado sólo detectó DENV-2 en muestras con infección por éste serotipo, confirmada por RT-PCR convencional, y no en las infectadas por DENV-1, demostrando la especificidad del ensayo y su utilidad en regiones con alta circulación de estos dos serotipos.

Tanto los antígenos (principalmente NS1) como el ARN del DENV se encuentran elevados durante los primeros días de la enfermedad y es en este tiempo donde se debe hacer la detección y diagnóstico molecular ${ }^{19}$. Las muestras de plasma analizadas en el estudio fueron tomadas antes del 5 día de fiebre, encontrando una alta viremia en el paciente con infección por DENV-2 (media $6 \mathrm{X} 10^{7}$ copias $/ \mathrm{mL}$ ). Esto es consistente con reportes previos que muestran que durante los días 3 a 6 de iniciados los síntomas en la infección por DENV-2 la viremia alcanza niveles entre $10^{6}$ a $10^{8}$ copias $/ \mathrm{mL}^{28,29}$.

La mayoría de los estuches comerciales de qPCR recomiendan ciertos equipos para su realización. Ya que el Eco ${ }^{\mathrm{TM}}$ no se encuentra listado entre los dispositivos que soportan la detección de DENV2 por el estuche comercial de Shanghai ZJ Bio-Tech Co, se comparó su rendimiento con el obtenido con el dispositivo ABI 7300, que sí es listado por el inserto del estuche. Se obtuvo una fuerte correlación positiva entre los resultados obtenidos con ambos equipos. En resumen, a pesar de las pocas muestras biológicas analizadas, la confiabilidad de los resultados obtenidos se basa en i. El uso de lisado celular y plasma de niños naturalmente infectados con DENV2 (Figura 1); ii. La introducción de controles externos como muestras infectadas con un serotipo diferente a la especificidad ofrecida por el estuche; iii. El adecuado funcionamiento de los controles internos y externos; iv. La utilización de un segundo dispositivo de amplificación (Figura 3).

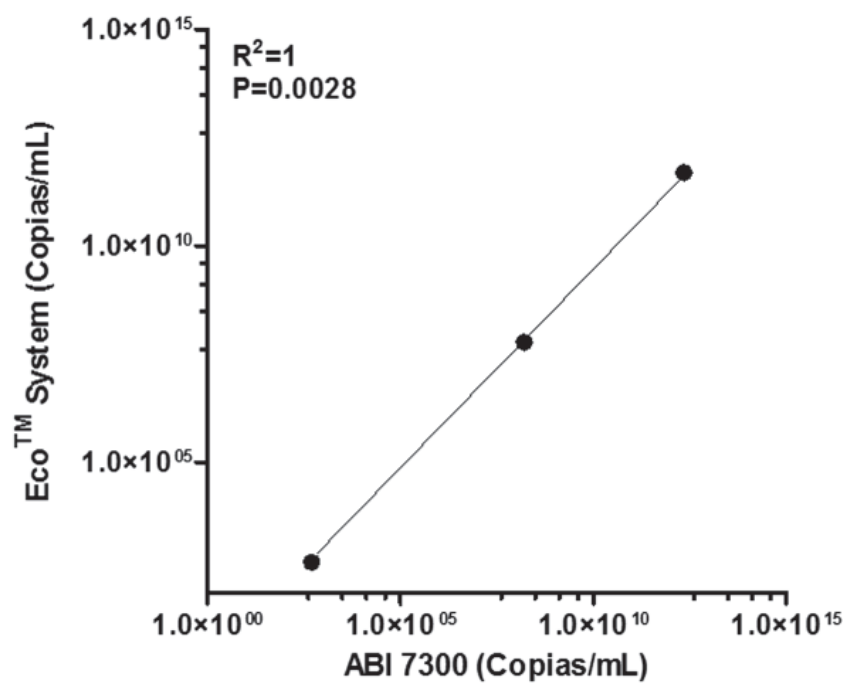

Figura 3. Correlación entre el número de copias $/ \mathrm{mL}$ de DENV-2 detectado por los dos equipos de qPCR. El promedio del duplicado de cada muestra, analizadas en los equipos $\mathrm{Eco}^{\mathrm{TM}}$ y $\mathrm{ABI} 7300$, fue comparado para hallar la correlación entre el número de copias $/ \mathrm{mL}$ de ARN de DENV-2. Cada punto representa el promedio del duplicado de una muestra. En el extremo superior izquierdo se muestra el grado de correlación. 
Debido a la importancia global del dengue y la necesidad de mejorar la capacidad diagnóstica e investigativa en áreas hiperendémicas, en varios laboratorios se han desarrollado ensayos de qPCR y en algunos casos se ha comparado su rendimiento tanto con protocolos de RT-PCR convencional ${ }^{21}$, como con estuches comerciales y de referencia (diseñado por el CDC) ${ }^{30}$. Sin embargo, a pesar de que éstos muestran buena funcionalidad, es difícil trasladar su aplicación a otros laboratorios debido a diferencias en los reactivos, dispositivos de qPCR o experiencia de los operadores. Los estuches comerciales representan una alternativa a este problema, pues garantizan la confiabilidad y reproducibilidad de los resul$\operatorname{tados}^{22}$, pero tienen limitaciones como el alto costo y la restricción de la aplicación del ensayo en dispositivos de qPCR no recomendados por el fabricante, al igual que el estuche de referencia del $\mathrm{CDC}^{31}$. Por todo lo anterior, se hace necesario no sólo el diseño de nuevos ensayos de qPCR para la detección de DENV, sino también la evaluación de los ya disponibles para determinar su desempeño en dispositivos de qPCR con los que se disponga localmente ${ }^{32}$.

En conclusión, los resultados demuestran el adecuado desempeño del $\mathrm{Eco}^{\mathrm{TM}}$ en la detección y cuantificación de DENV-2 en plasma y lisado celular usando un estuche comercial, por lo que la implementación de ésta técnica servirá para impulsar grandemente estudios virológicos, inmunes y moleculares a nivel regional.

\section{Agradecimientos}

A Frank Barreiro, Laboratorio de Medicina Genómica, por la adquisición y análisis de los datos en el equipo ABI 7300. Éste trabajo fue financiado por la Vicerrectoría de Investigación y Proyección Social de la Universidad Surcolombiana.

\section{Bibliografia}

1. Bhatt S, Gething PW, Brady OJ, et al. The global distribution and burden of dengue. Nature. 2013; 496(7446):504-7.

2. SIVIGILA. Casos por evento en departamento y municipios. Instituto Nacional de Salud, 2012.

3. Rothman AL. Dengue: defining protective versus pathologic immunity. The Journal of clinical investigation. $2004 ; 113(7): 946-51$.

4. Simmons CP, Farrar JJ, Nguyen v V, Wills B. Dengue. The New England journal of medicine. 2012;366(15): 1423-32.

5. Lanciotti RS, Calisher CH, Gubler DJ, Chang GJ, Vorndam AV. Rapid detection and typing of dengue viruses from clinical samples by using reverse transcriptase-polymerase chain reaction. Journal of clinical microbiology. 1992;30(3):545-51.

6. Bustin SA. Absolute quantification of mRNA using realtime reverse transcription polymerase chain reaction assays. Journal of molecular endocrinology. $2000 ; 25(2)$ : 169-93.

7. Wong ML, Medrano JF. Real-time PCR for mRNA quantitation. BioTechniques. 2005;39(1):75-85.

8. Heid CA, Stevens J, Livak KJ, Williams PM. Real time quantitative PCR. Genome research. 1996;6(10): 986-94.

9. Gurukumar KR, Priyadarshini D, Patil JA, et al. Development of real time PCR for detection and quantitation of Dengue Viruses. Virology journal. 2009;6:10.

10. Dos Santos HW, Poloni TR, Souza KP, et al. A simple one-step real-time RT-PCR for diagnosis of dengue virus infection. Journal of medical virology. 2008;80(8): 1426-33.

11. Chien LJ, Liao TL, Shu PY, Huang JH, Gubler DJ, Chang GJ. Development of real-time reverse transcriptase PCR assays to detect and serotype dengue viruses. Journal of clinical microbiology. 2006;44(4):1295-304.

12. Sadon $N$, Delers $A$, Jarman RG, et al. A new quantitative RT-PCR method for sensitive detection of dengue virus in serum samples. Journal of virological methods. $2008 ; 153(1): 1-6$.

13. Lave T, Emmerich P, Schmitz H. Detection of dengue virus RNA in patients after primary or secondary dengue infection by using the TaqMan automated amplification system. Journal of clinical microbiology. 1999; 37(8):2543-7.

14. De Paula SO, de Melo Lima C, Torres MP, Pereira MR, Lopes da Fonseca BA. One-Step RT-PCR protocols improve the rate of dengue diagnosis compared to TwoStep RT-PCR approaches. Journal of clinical virology : the official publication of the Pan American Society for Clinical Virology. 2004;30(4):297-301.

15. Mishra B, Sharma M, Pujhari SK, Appannanavar SB, Ratho RK. Clinical applicability of single-tube multiplex reverse-transcriptase PCR in dengue virus diagnosis and serotyping. Journal of clinical laboratory analysis. $2011 ; 25(2): 76-8$.

16. Callahan JD, Wu SJ, Dion-Schultz A, et al. Development and evaluation of serotype- and group-specific fluorogenic reverse transcriptase PCR (TaqMan) assays for dengue virus. Journal of clinical microbiology. 2001;39(11):4119-24.

17. Ito M, Takasaki T, Yamada K, Nerome R, Tajima S, Kurane I. Development and evaluation of fluorogenic TaqMan reverse transcriptase PCR assays for detection of dengue virus types 1 to 4 . Journal of clinical microbiology. 2004;42(12):5935-7.

18. Centers for Disease Control and Prevention. DENV-1-4 real-time RT-PCR assay for detection and serotype identi?cation of dengue virus. CDC package insert. Catalog no. KK0128. Centers for Disease Control and Prevention, Atlanta, GA.

19. Santiago GA, Vergne E, Quiles $Y$, et al. Analytical and clinical performance of the CDC real time RT-PCR assay for detection and typing of dengue virus. PLoS neglected tropical diseases. 2013;7(7):e2311.

20. Waggoner JJ, Abeynayake J, Sahoo MK, et al. Development of an internally controlled real-time reverse transcriptase PCR assay for pan-dengue virus detection and comparison of four molecular dengue virus detection assays. Journal of clinical microbiology. 2013; 51(7):2172-81.

21. Waggoner JJ, Abeynayake J, Sahoo MK, et al. Singlereaction, multiplex, real-time rt-PCR for the detection, quantitation, and serotyping of dengue viruses. PLoS neglected tropical diseases. 2013;7(4):e2116. 
22. Levi JE, Tateno AF, Machado AF, et al. Evaluation of a commercial real-time PCR kit for detection of dengue virus in samples collected during an outbreak in Goiania, Central Brazil, in 2005. Journal of clinical microbiology. 2007;45(6):1893-7.

23. Harris E, Roberts TG, Smith L, et al. Typing of dengue viruses in clinical specimens and mosquitoes by singletube multiplex reverse transcriptase PCR. Journal of clinical microbiology. 1998;36(9):2634-9.

24. Shanghai ZJ Bio-Tech Co., Ltd. Dengue Virus GeneralType Real Time RT-PCR Kit. Catalog ER-0063-04. Shanghai ZJ Bio-Tech Co.

25. Kong YY, Thay $\mathrm{CH}$, Tin TC, Devi S. Rapid detection, serotyping and quantitation of dengue viruses by TaqMan real-time one-step RT-PCR. Journal of virological methods. 2006;138(1-2):123-30.

26. Nolan T, Hands RE, Bustin SA. Quantification of mRNA using real-time RT-PCR. Nature protocols. 2006; 1(3):1559-82.
27. VanGuilder HD, Vrana KE, Freeman WM. Twenty-five years of quantitative PCR for gene expression analysis. BioTechniques. 2008;44(5):619-26.

28. Duyen HT, Ngoc TV, Ha do T, et al. Kinetics of plasma viremia and soluble nonstructural protein 1 concentrations in dengue: differential effects according to serotype and immune status. The Journal of infectious diseases. $2011 ; 203(9): 1292-300$.

29. Tricou V, Vu HT, Quynh NV, et al. Comparison of two dengue NS1 rapid tests for sensitivity, specificity and relationship to viraemia and antibody responses. BMC infectious diseases. 2010;10:142.

30. Waggoner JJ, Abeynayake J, Sahoo MK, et al. Comparison of the FDA-approved CDC DENV-1-4 realtime reverse transcription-PCR with a laboratorydeveloped assay for dengue virus detection and serotyping. Journal of clinical microbiology. 2013;51(10):3418-20. 